University of Nebraska - Lincoln

DigitalCommons@University of Nebraska - Lincoln

U.S. Navy Research

U.S. Department of Defense

2011

The utility of Shewanella japonica for microbial fuel cells

Justin C. Biffinger

US Naval Research Laboratory, justin.biffinger@nrl.navy.mil

Lisa A. Fitzgerald

US Naval Research Laboratory, lisa.fitzgerald@nrl.navy.mil

Ricky Ray

US Naval Research Laboratory

Brenda J. Little

Naval Research Laboratory, blittle@nrlssc.navy.mil

Stephen E. Lizewski

US Naval Research Laboratory

See next page for additional authors

Follow this and additional works at: https://digitalcommons.unl.edu/usnavyresearch

Part of the Operations Research, Systems Engineering and Industrial Engineering Commons

Biffinger, Justin C.; Fitzgerald, Lisa A.; Ray, Ricky; Little, Brenda J.; Lizewski, Stephen E.; Petersen, Emily R.; Ringeisen, Bradley R.; Sanders, Wesley C.; Sheehan, Paul E.; Pietron, Jeremy J.; Baldwin, Jeffrey W.; Nadeau, Lloyd J.; Johnson, Glenn R.; Ribbens, Meghann; Finkel, Steven E.; and Nealson, Kenneth H., "The utility of Shewanella japonica for microbial fuel cells" (2011). U.S. Navy Research. 6.

https://digitalcommons.unl.edu/usnavyresearch/6

This Article is brought to you for free and open access by the U.S. Department of Defense at DigitalCommons@University of Nebraska - Lincoln. It has been accepted for inclusion in U.S. Navy Research by an authorized administrator of DigitalCommons@University of Nebraska - Lincoln. 


\section{Authors}

Justin C. Biffinger, Lisa A. Fitzgerald, Ricky Ray, Brenda J. Little, Stephen E. Lizewski, Emily R. Petersen, Bradley R. Ringeisen, Wesley C. Sanders, Paul E. Sheehan, Jeremy J. Pietron, Jeffrey W. Baldwin, Lloyd J. Nadeau, Glenn R. Johnson, Meghann Ribbens, Steven E. Finkel, and Kenneth H. Nealson 


\title{
The utility of Shewanella japonica for microbial fuel cells
}

\author{
Justin C. Biffinger ${ }^{\mathrm{a}}$, Lisa A. Fitzgerald ${ }^{\mathrm{a}}$, Ricky Ray ${ }^{\mathrm{b}}$, Brenda J. Little ${ }^{\mathrm{b}}$, Stephen E. Lizewski ${ }^{\mathrm{a}}$, \\ Emily R. Petersen ${ }^{c}$, Bradley R. Ringeisen ${ }^{a}$, Wesley C. Sanders ${ }^{a}$, Paul E. Sheehan ${ }^{\text {a }}$, Jeremy J. Pietron ${ }^{\mathrm{a}}$, \\ Jeffrey W. Baldwin ${ }^{\mathrm{d}}$, Lloyd J. Nadeau ${ }^{\mathrm{e}}$, Glenn R. Johnson ${ }^{\mathrm{e}}$, Meghann Ribbens ${ }^{\mathrm{f}}$, Steven E. Finkel ${ }^{\mathrm{f}}$, \\ Kenneth H. Nealson ${ }^{\mathrm{g}}$
}

${ }^{a}$ Chemistry Division, US Naval Research Laboratory, 4555 Overlook Avenue, SW, Washington, DC 20375, USA

${ }^{\mathrm{b}}$ Oceanography Division, US Naval Research Laboratory, Bldg 1009, John C. Stennis Space Center, MS 39529, USA

${ }^{\mathrm{c}}$ Nova Research Inc., 1900 Elkin St., Suite 230, Alexandria, VA 22308, USA

${ }^{\mathrm{d}}$ Acoustics Division, US Naval Research Laboratory, 4555 Overlook Avenue, SW, Washington, DC 20375, USA

${ }^{\mathrm{e}}$ Microbiology \& Applied Biochemistry Division, Air Force Research Laboratory, 139 Barnes Drive, Suite \#2, Tyndall AFB, FL 32403, USA

${ }^{\mathrm{f}}$ Molecular and Computational Biology Section, Department of Biological Sciences, University of Southern California, Los Angeles, CA 90089-2910, USA

${ }^{\mathrm{g}}$ Department of Earth Sciences, University of Southern California, Los Angeles, CA 90089-0740, USA

\section{A R T I C L E I N F O}

\section{Article history:}

Received 25 March 2010

Received in revised form 9 June 2010

Accepted 17 June 2010

\section{Keywords:}

Microbial fuel cell

Shewanella

Sucrose

Mediators

Carbohydrate

\begin{abstract}
A B S T R A C T
Shewanella-containing microbial fuel cells (MFCs) typically use the fresh water wild-type strain Shewanella oneidensis MR-1 due to its metabolic diversity and facultative oxidant tolerance. However, S. oneidensis MR-1 is not capable of metabolizing polysaccharides for extracellular electron transfer. The applicability of Shewanella japonica (an agar-lytic Shewanella strain) for power applications was analyzed using a diverse array of carbon sources for current generation from MFCs, cellular physiological responses at an electrode surface, biofilm formation, and the presence of soluble extracellular mediators for electron transfer to carbon electrodes. Critically, air-exposed S. japonica utilizes biosynthesized extracellular mediators for electron transfer to carbon electrodes with sucrose as the sole carbon source.
\end{abstract}

Published by Elsevier Ltd.

\section{Introduction}

Developing carbon-neutral renewable energy sources is an important research area for alternative power systems. Electricity generated from fuel cells has found large scale application in all aspects of transportation as well as stationary power supplies (Larminie and Dicks, 2003). Biological fuel cells are an alternative technology to commercial $\mathrm{H}_{2} / \mathrm{O}_{2}$ proton exchange membrane fuel cells in that they operate at ambient temperatures, in aqueous environments, and with minimal energy input. Microbial fuel cell (MFC) technology has rapidly advanced in the last five years with an outpouring of both new devices and identification of microbial strains or consortia that convert a variety of carbon sources directly into electricity (Watanabe, 2008; Harnisch and Schroder, 2009; Zhao et al., 2009). A particularly attractive facet of MFCs is their use of many fuels, even wastewater, to generate power. This is a welcome relief to the stringent fuel purity requirements of most conventional proton exchange membrane (PEM) fuel cells. However, MFCs typically suffer from low current densities (Logan

Corresponding author. Tel.: +1 202767 2398; fax: +1 2024048119

E-mail address: justin.biffinger@nrl.navy.mil (J.C. Biffinger). and Regan, 2006). To address this issue, new electrode materials and/or new microbes or consortia need to be developed.

Bacteria of the groups Shewanellaceae and Geobacteraceae are classic models in MFC research because of the breadth of knowledge about their metabolism and versatility (Lovley, 2006; Fredrickson et al., 2008). The compatibility of fuel types in a given MFC is defined by the metabolism of the microorganism coupled to extracellular electron transfer to generate electrical output but is not necessarily linked to metal reduction (Richter et al., 2007). Geobacter-containing MFCs generate high Coulombic efficiencies (Call et al., 2009) but require punctilious anaerobic conditions, limiting their applicability. Conversely, Shewanella-containing MFCs can be operated with air-exposed cultures. Shewanella sp. respire a wide range of inorganic and organic compounds through many mechanisms, including the use of mediators, to facilitate electron transfer outside the cell membrane (Schröder, 2007). Therefore, Shewanella sp. can reduce solid substrates through indirect mechanisms, unlike Geobacter sp. which require direct contact to the electrode surface (Lovley, 2006). Shewanella sp. are an attractive bacterium for MFCs because they can biosynthesize redox mediators and operate under diverse environmental conditions (Fredrickson et al., 2008). Systems relying on artificial mediators to decrease the overpotential for electron transfer are limited by 
irreversible deactivation and cost due to the periodic addition of the mediators. However, bacterial systems that generate their own mediators for extracellular electron transfer are feasible for autonomous power sources.

Shewanella oneidensis MR-1 is the archetype for the genus and is frequently used as a model in MFCs. S. oneidensis MR-1 is a fresh water microbe and was initially isolated from Lake Oneida, New York in the early 1980s (Myers and Nealson, 1988). Research in both fundamental electron transfer pathways and systems analysis has been explored but unfortunately, the bacterium is unable to survive in high salinity environments (Fredrickson et al., 2008). Interest in generating electricity from marine environments necessitates the use of marine strains of Shewanella for electricity production within MFCs. Recently, a study has shown that Shewanella marisflavi EP1 is capable of generating power at a high ionic strength (up to $8 \% \mathrm{NaCl}$ ) but only lactate was used as a carbon source (Huang et al., 2010). Shewanella japonica is a marine microbe isolated from mussels in the Sea of Japan (Ivanova et al., 2001). In addition to metabolizing agar, S. japonica utilizes D-galactose, D-fructose, glucose, and sucrose in growth experiments suggesting that these carbon sources could be converted to electricity, provided these metabolic pathways are coupled to extracellular electron transfer processes.

One important advance that could increase the competitiveness of MFCs in energy production applications would be the direct conversion of polysaccharides into electricity. Only 2-3 strains of bacteria (as well some spontaneous mutants of these strains) have been described in the literature that convert glucose directly to power within MFCs (Chaudhuri and Lovley, 2003; Biffinger et al., 2008a,b; Zuo et al., 2008). Enterobacter cloacae was the first native strain of bacteria shown to generate power from cellulose in a MFC (Rezaei et al., 2009). Presently, di- and polysaccharide utilization can only be accomplished by enhanced bacterial consortia (Ishii et al., 2008; Ren et al., 2008). The agar-lytic capacity of S. japonica makes it a promising candidate for generating power from polysaccharides.

This manuscript determines for the first time that $S$. japonica can convert di- and polysaccharides into electrical current. The mechanism for electron transfer is probed as well as the response of $S$. japonica to a carbon electrode surface in an operating MFC. An analysis of all these data suggests that $S$. japonica could be used in MFCs utilizing polysaccharides, but the strain may be limited by the presence of electron transfer mediators not initially present in cultures.

\section{Methods}

\subsection{Solutions and media}

Stock solutions of sodium lactate $(1.95 \mathrm{M})$, sodium acetate $(1.95 \mathrm{M}), 1 \%$ cellobiose, sucrose $(1 \mathrm{M}), 2 \%$ starch, and sodium citrate $(0.5 \mathrm{M})$ were sterilized by autoclaving for $13 \mathrm{~min}$ at $121^{\circ} \mathrm{C}$ and adjusted to $\mathrm{pH} 7$. A D-glucose $(1 \mathrm{M})$ stock solution was sterilized with a $0.2 \mu \mathrm{m}$ cellulose nitrate filter. Marine broth (MB) and marine agar (MA) were used for liquid cultures and plates, respectively (Difco). The solvent for each solution was Millipore $18 \mathrm{M} \Omega$ water.

\subsection{Cell culture conditions}

S. japonica (ATCC: BAA-316) was grown from a single colony isolated from MA inoculated from a $-80^{\circ} \mathrm{C}$ glycerol stock culture. Stabs of $S$. japonica in MA were used to inoculate liquid culture media in MFCs. Stabs were only used over a period of one month. S. japonica was transferred to $50 \mathrm{~mL}$ of $\mathrm{MB}$ in a $125 \mathrm{~mL}$ flask and incubated exposed to air at $27^{\circ} \mathrm{C}$ at $100 \mathrm{rpm}$. Experimental cultures from stabs and frozen stocks were acclimated to growth in media by subculturing once after $30 \mathrm{~h}$ before being used in miniature MFC and voltage based screening assay (VBSA) experiments.

\subsection{VBSA construction and data acquisition}

Dimensions and fabrication of the VBSA were published previously (Biffinger et al., 2009). The diameter of each well was $0.8 \mathrm{~cm}$ with a depth of $1.3 \mathrm{~cm}$. Fully assembled, each well contains a maximum of $600 \mu \mathrm{L}$. The anodes were constructed from a titanium metal sheet (active electrode area, $0.3 \times 0.3 \mathrm{~cm}$ ) coated with a conductive carbon ink. The carbon ink contained $30 \mathrm{mg}$ carbon black, $300 \mu \mathrm{L}$ 2-propanol, $300 \mu \mathrm{L} 5 \%$ Nafion Solution in water, and $2 \mathrm{~mL}$ of de-ionized water. The cathode system was graphite paper in $50 \mathrm{mM}$ potassium ferricyanide (dissolved in $100 \mathrm{mM}$ phosphate buffer at $\mathrm{pH}$ 7.0). Each experiment was completed using a nine-well VBSA apparatus. Experiments with no addition of carbon source were designated as blanks and were control experiments. Electrodes used for environmental scanning electron microscopy (ESEM) imaging were removed after $100 \mathrm{~h}$ of operation. Voltages were measured across a $100 \mathrm{k} \Omega$ resistor (in a nine-resistor bank made for simultaneous voltage measurements) and were recorded with a high-resolution data acquisition module (I/O tech, personal daq/54) every two minutes. The measured voltage was converted to current using Ohm's law (Voltage = Current*Resistance). Each set of VBSA biofilm experiments were performed twice with each VBSA setup containing two experiments per each carbon source.

\subsection{Biofilm growth and staining}

Overnight cultures of $S$. japonica and S. oneidensis MR-1 were established by inoculating $5 \mathrm{~mL}$ MB or LB, respectively, from a frozen stock in test tubes and were agitated in a cell culture roller. These cultures were diluted 100 -fold in the appropriate growth medium, and $1 \mathrm{~mL}$ aliquots were removed for static incubation. After three days of static incubation at room temperature $\left(20^{\circ} \mathrm{C} \pm 1{ }^{\circ} \mathrm{C}\right.$ ) for $\mathrm{S}$. japonica or $30^{\circ} \mathrm{C}$ for S. oneidensis MR-1, supernatants were discarded, and each tube was stained with $1.25 \mathrm{~mL}$ $0.1 \%$ crystal violet for $30 \mathrm{~min}$. Biofilms in tubes were rinsed to remove excess stain, dried and imaged.

\subsection{Miniature MFC setup and data collection}

The general dimensions and setup for the mini-MFC apparatus were described previously (Ringeisen et al., 2006). Two identical miniature MFC systems were operated simultaneously for each experiment. The electrodes within the fuel cell chambers were low-density graphite felt $(0.13 \mathrm{~g}$, Electrosynthesis Company, Lancaster, NY; $0.47 \mathrm{~m}^{2} / \mathrm{g}$ ) and were connected with titanium wires to an external load. The anode and cathode chambers were separated by Nafion ${ }^{\circledR}-117$ (The Fuel Cell Store). Membranes were pre-treated for $1 \mathrm{~h}$ each in hot de-ionized (DI) water, $3 \%$ hydrogen peroxide, $1 \mathrm{M}$ sulfuric acid, and DI water again. The anolyte and catholyte were passed through the chambers at a flow rate of 1$2 \mathrm{~mL} / \mathrm{min}$ using a peristaltic pump. The catholyte for each fuel cell was a $50 \mathrm{mM}$ potassium ferricyanide solution in $100 \mathrm{mM}$ phosphate buffer ( $\mathrm{pH} 7.2$ ) using uncoated graphite felt (GF) electrodes. All fuel cells were run at $25 \pm 1^{\circ} \mathrm{C}$. Fuel cells were operated simultaneously, inoculated from identical $50 \mathrm{~mL}$ cultures of $S$. japonica either with or without the addition of riboflavin $(1 \mu \mathrm{M})$. Riboflavin-exposed cultures were wrapped in aluminum foil to limit ambient light exposure. Sucrose was added to a concentration of $2 \mathrm{mM}$ in each anode culture flask at 48 and $124 \mathrm{~h}$ into MFC operation. Samples were removed periodically through each experiment for analysis by HPLC (Varian, Inc.) with a refractive index detector. 
The mobile phase was a $0.005 \mathrm{M}$ sulfuric acid solution and the column was a PL Hi-Plex $\mathrm{H}^{+}$ion exchange column, at $65^{\circ} \mathrm{C}$, with a flow rate of $0.6 \mathrm{~mL} / \mathrm{min}$. Peaks for sucrose and acetate were calibrated using known standards.

\subsection{Imaging S. japonica biofilms from the VBSA}

Environmental scanning electron microscopy (ESEM) of carbon surfaces on the titanium anodes was performed at the Naval Research Laboratory, Stennis Space Center, MS (NRLSSC). Unattached biomass was removed by washing each anode with three separate $1 \mathrm{~mL}$ aliquots of phosphate buffered saline solution at the Naval Research Laboratory, Washington, DC (NRLDC). Each anode was placed in $2 \mathrm{~mL}$ of $4 \%$ cacodylate buffered glutaraldehyde fixative (Ray et al., 1997) at NRLDC and fixed for at least $24 \mathrm{~h}$ at $4{ }^{\circ} \mathrm{C}$ prior to shipment to NRLSSC without further manipulations. ESEM imaging procedures were performed as previously described (Biffinger et al., 2009).

\subsection{SEM and AFM imaging}

A $125 \mathrm{~mL}$ Erlenmeyer flask containing $50 \mathrm{~mL}$ marine broth was used to initiate a $S$. japonica culture from an agar stab. The culture was incubated for $48 \mathrm{~h}$ at $25^{\circ} \mathrm{C}$ after which the $1 \mathrm{~mL}$ of cells was harvested by centrifugation at $5 \mathrm{~K} \mathrm{rpm}$ for $3 \mathrm{~min}$. The cell pellet was washed 5 times with $1 \mathrm{~mL}$ of distilled water. The cells were resuspended with $1 \mathrm{~mL}$ distilled water and $2 \mu \mathrm{L}$ was deposited onto a silicon oxide wafer for imaging. SEM micrographs were collected using a LEO Supra 55 microscope using the in-lens detector and with the primary beam voltage set to $10 \mathrm{kV}$. The primary beam voltage was chosen to give maximum contrast and reduced charging of the sample. The sample prepared for SEM imaging was dehydrated in acetone. Atomic force microscopy (AFM) images were collected using an Autoprobe CP Research AFM equipped with a microlever contact mode tip (force constant of $0.01 \mathrm{~N} \mathrm{~m}^{-1}$ ), both manufactured by Thermomicroscopes. The AFM was operated in contact mode with a $3 \mathrm{nN}$ set point, $0.4 \mathrm{~Hz}$ scan rate, and $512 \times 512$ pixel resolution.

\subsection{Identification of riboflavin from mini-MFC experiments}

The HPLC analysis of culture supernatants was described previously (Biffinger et al., 2008a,b). The instrumentation included Agilent (1100 series) chromatography components (Santa Clara, CA), a quaternary pump for mobile phase delivery and diode array detector (DAD) for monitoring elutent and collecting UV-Vis spectra. An Altima Phenyl column $(250 \mathrm{~mm} \times 4.6 \mathrm{~mm}, 5 \mu \mathrm{m}$ support; Alltech Assoc., Deerfield Ill) was used. The mobile phase was formic acid (0.1\%): methanol (70:30, $\left.1 \mathrm{~mL} \mathrm{~min}^{-1}\right)$. The eluent was monitored at $210 \mathrm{~nm}$ and absorbance was recorded for chromatograms. For the sample preparation, the culture supernatants were first clarified using centrifugation to remove bacteria and insoluble material. Following centrifugation, samples were concentrated using a C18 solid phase extraction (SPE) cartridge (100 mg scale, Suplelco, Bellefonte, PA) that had been preconditioned using manufacturer's recommendations. For SPE, $2 \mathrm{~mL}$ of culture supernatant was passed through the resin, polar compounds were washed from the matrix with an equal volume of water and then the non-polar molecules eluted with $0.5 \mathrm{~mL}$ methanol, and then analyzed using HPLC.

\subsection{Electrochemistry of supernatant for mediator expression}

A subculture from a four-day-old culture of S. japonica was grown for two days. The subculture was centrifuged for $10 \mathrm{~min}$ $\left(5500 \mathrm{~g}, 15^{\circ} \mathrm{C}\right.$ ) and the supernatant filtered through a $0.2 \mu \mathrm{m}$ poly- tetrafluoroethylene (PTFE) filter prior to electrochemical analysis. Blank MB samples were obtained from the same growth medium used for the $S$. japonica culture. In a three-electrode electrochemical cell, a polished 1.6-mm diameter polycrystalline gold electrode was used as the working electrode, Pt gauze was used as the counter electrode and a $\mathrm{Ag} / \mathrm{AgCl}$ reference electrode (Bioanalytical Systems) completed the electrochemical cell. Potentials were corrected and reported versus the reversible hydrogen electrode (RHE). The electrolytes (media) were continuously sparged with either $\mathrm{Ar}$ or $\mathrm{O}_{2}$ to maintain anoxic or aerobic conditions during electrochemical background and electrocatalytic oxygen reduction measurements, respectively. The working electrode was polished before each measurement using an aqueous slurry of $0.05 \mu \mathrm{m}$ alumina powder (Buehler) on a polishing cloth and sonicated in DI water to remove residual alumina from the electrode surface. Сyclic voltammetric scan rates were $100 \mathrm{mV} / \mathrm{s}$.

\section{Results and discussion}

\subsection{Imaging of S. japonica}

Bacterial nanofilamentous appendages have been studied for their role in electron transfer to solid substrates (Gorby et al., 2006; Reguera et al., 2006), biofilm formation (Proft and Baker, 2009), or cellular communication (Jelsbak and Sogaard-Andersen, 2003). Images of air exposed S. japonica were collected by either SEM (Fig. 1A and B) or AFM (Fig. 1C) in contact mode. S. japonica is rod-shaped ( $\sim 1 \mu \mathrm{m}$ in length) with multiple flagella and pilitype structures expressed around the cell body. Generally, images of S. japonica compared to S. oneidensis MR-1 (data not shown) prepared using identical protocols indicate that there are more nanofilamentous structures expressed by $S$. japonica than $S$. oneidensis MR-1. Since pili are essential for biofilm formation, it may be expected that $S$. japonica will form thick biofilms (Thormann et al., 2004). Maximum lengths for flagella were between 10 and $15 \mu \mathrm{m}$ while pili lengths were between 3 and $4 \mu \mathrm{m}$. In addition to the filamentous appendages, $S$. japonica produced a large sheath-like material (30-40 $\mu \mathrm{m} \times 1 \mu \mathrm{m})$. Except for one example of $S$. oneidensis MR-1 grown at $3{ }^{\circ} \mathrm{C}$ (Abboud et al., 2005), sheath formation is not common for the Shewanellacae family and the exact role of the structure is currently unknown.

\subsection{Screening of nutrients for current production by S. japonica}

The ability of a bacterium to reduce inorganic oxides does not necessarily translate into current producing capabilities (Richter et al., 2007). Current output from S. japonica was assessed using monosaccharides (glucose, fructose), disaccharides (sucrose, cellobiose), carboxylic acids (acetate, lactate, citrate), and a polysaccharide (starch) using a VBSA. Within this single miniature modular platform, nine simultaneous MFCs could be operated against a single cathode/reference electrode (Biffinger et al., 2009). For the 9well VBSA experiments, the amount of biofilm formation was determined at the end of each screening experiment as well as the current generated from air-exposed anodes with time (data not shown).

Anodes containing S. japonica in the absence of riboflavin and presence of $1 \mu \mathrm{M}$ riboflavin were imaged by ESEM (data not shown). Fig. 2A and B presents the VBSA current versus time data for each carbon source. All experiments were shielded from light because of the sensitivity of riboflavin to ambient light. Riboflavin was chosen because of its potential role in mediating electron transfer in S. oneidensis (Biffinger et al., 2008; Marsili et al., 2008; von Canstein et al., 2008; Ramasamy et al., 2009). The maximum current generated from non-mediated S. japonica MFCs was less 

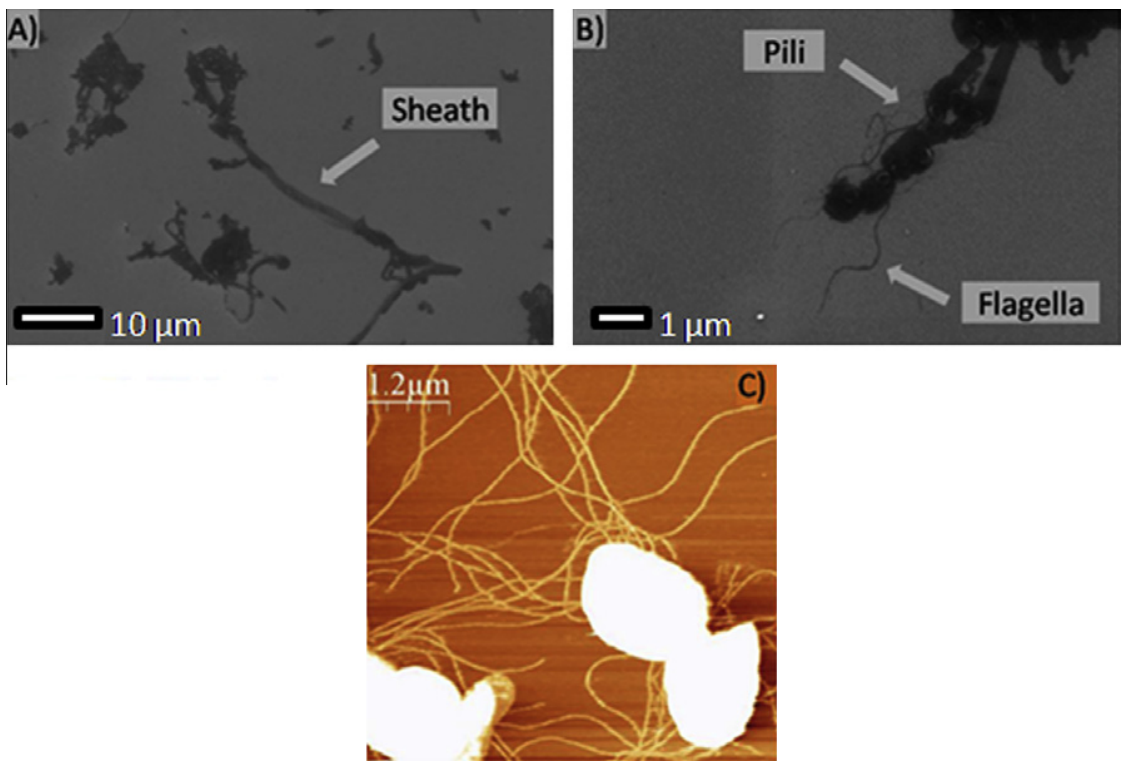

Fig. 1. SEM (A and B) and AFM (C) images of S. japonica.
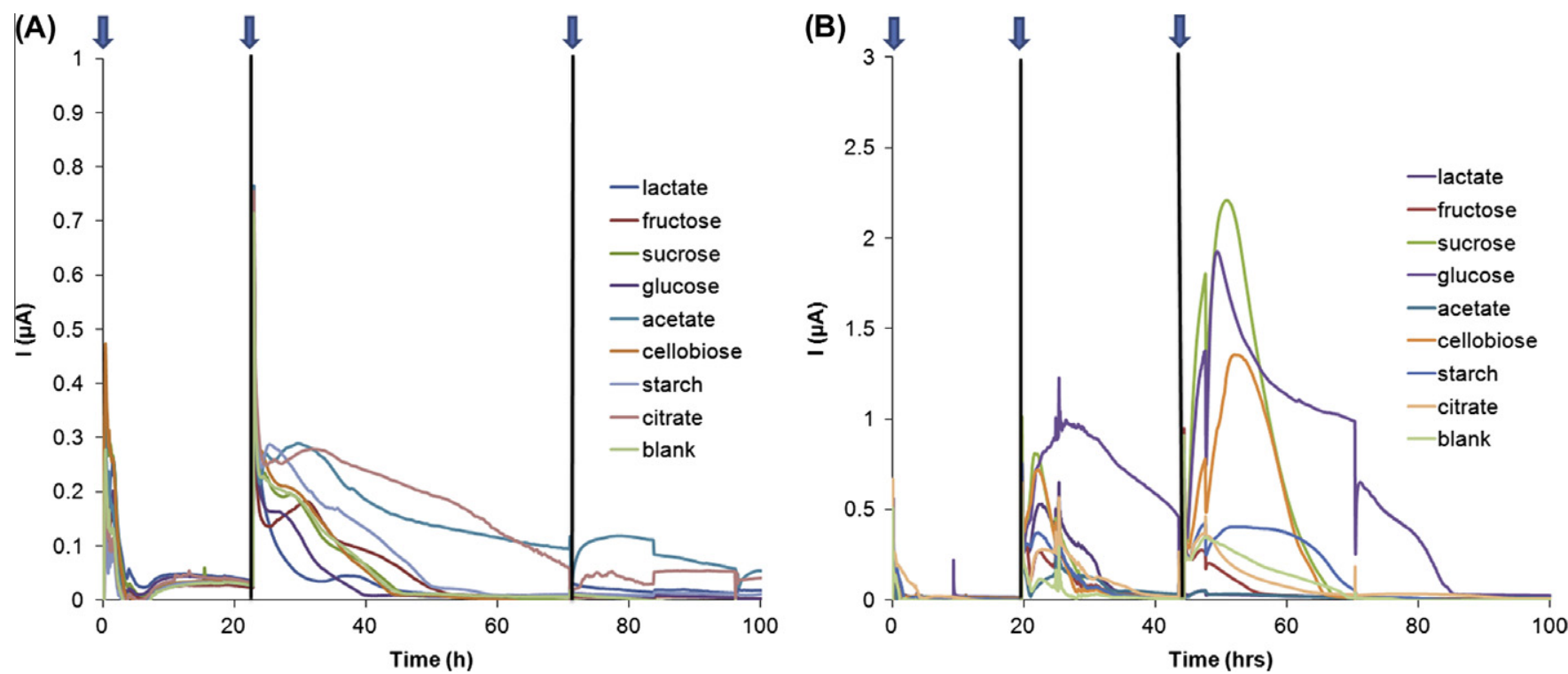

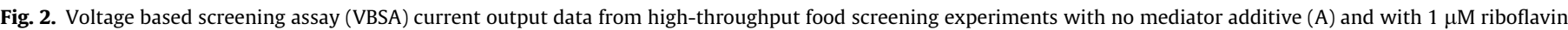
(B). Footnote: Addition of $10 \mathrm{mM}$ carbon sources is indicated by vertical lines.

than $0.3 \mu \mathrm{A}$ throughout the duration of the experiment; while mediated electron transfer resulted in defined current spikes after the addition of carbon sources with the largest current output after the addition of sucrose ( $>2 \mu \mathrm{A}$ ) (Fig. $2 \mathrm{~B}$ ). The results from the nonmediated VBSA (Fig. 2A) indicate that none of the carbon substrates were used efficiently by $S$. japonica for current output after $100 \mathrm{~h}$. On the other hand, in the presence of $1 \mu \mathrm{M}$ riboflavin $S$. japonica was capable of generating current immediately from sucrose, glucose, cellobiose, and to a lesser extent, starch (Fig. 2B).

Even though Shewanella sp. can deliver electrons through direct contact as well as at a distance through external mediators, biofilm formation will generate higher current densities due to the proximity of the microbe to the electrode surface (Franks et al., 2009). ESEM images of electrode surfaces from each of the active anode chambers of the VBSA confirms that there was no significant biofilm formation in most of the unmediated MFCs, while sparse biofilms were observed with glucose-exposed S. japonica (data not shown). There was an overall increase in cellular attachment to the electrode surfaces when S. japonica was exposed to riboflavin with the following carbon sources: acetate, cellobiose, and fructose. However, the opposite was true for glucose. In addition, cellobiose and fructose exposure resulted in the formation of a sheath type structure. Biofilm formation did not result in power output in the case of acetate, indicating that S. japonica cannot use acetate as a carbon substrate for current production.

The lack of biofilm formation on the electrode contradicted results observed in the culture tube. S. japonica forms thicker biofilms in standard culture tubes than S. oneidensis MR-1 (data not shown). During the VBSA experiments there was no significant biofilm formation on the electrode surface suggesting that S.japonica is presumably experiencing voltage based repulsion to the electrode surface in an operational MFC. Previous work with S. oneidensis MR-1 
confirms that thick biofilms can be observed using our current electrode preparation protocol (Biffinger et al., 2009; Bouhenni et al., 2010) thus S. japonica does not form significant biofilms on active electrodes. Therefore, under these particular conditions, the increase in pili expression, as seen from the micrographs, does not lead to increased biofilm formation in an operational MFC and thus may not play a direct role in electron transfer.

\subsection{Utilization of sucrose for electricity output in the mini-MFC}

The necessity for the addition of homogenous organic redox active mediators (i.e., riboflavin) to produce current responses is both promising and concerning. S. japonica utilized simple carbohydrates, and both di- and polysaccharides to generate current in a MFC in the presence of riboflavin but no significant current was observed without riboflavin. To study the maximum current generated from $S$. japonica exposed to sucrose with and without the addition of riboflavin, two additional MFC experiments were performed in identical miniature MFCs (mini-MFC). The mini-MFC is an active flow system that generates high current densities (per volume) and shows good reproducibility from MFC to MFC as well as negates the need for substantial biofilm formation to generate maximum power density (Ringeisen et al., 2006; Biffinger et al., 2007; Biffinger et al., 2008). Two mini-MFCs were operated simultaneously (with and without the addition of $1 \mu \mathrm{M}$ riboflavin) using the same catholyte to eliminate variation derived from the cathodic reaction between experiments. The current generated from each mini-MFC versus time is shown in Fig. 3 using an $820 \Omega$ external resistor on each MFC. Additions of sucrose were performed at the onset of the experiment, at 48 and $124 \mathrm{~h}$.

The current from the mini-MFC with $1 \mu \mathrm{M}$ riboflavin was consistently higher than the MFC without riboflavin during the first $75 \mathrm{~h}$ of operation. After the second addition of sucrose ( $48 \mathrm{~h}$ of operation), there was an immediate current response for the MFC with riboflavin that is consistent with the results from the VBSA experiment (Fig. 2B). However, after $75 \mathrm{~h}$ a reproducible increase in current density (per volume) as high as $0.66 \mathrm{~mA} / \mathrm{cm}^{3}$ was observed from the mini-MFC without riboflavin. The third addition of sucrose at $124 \mathrm{~h}$ confirmed that sucrose was being utilized by S. japonica for extracellular electron transfer.

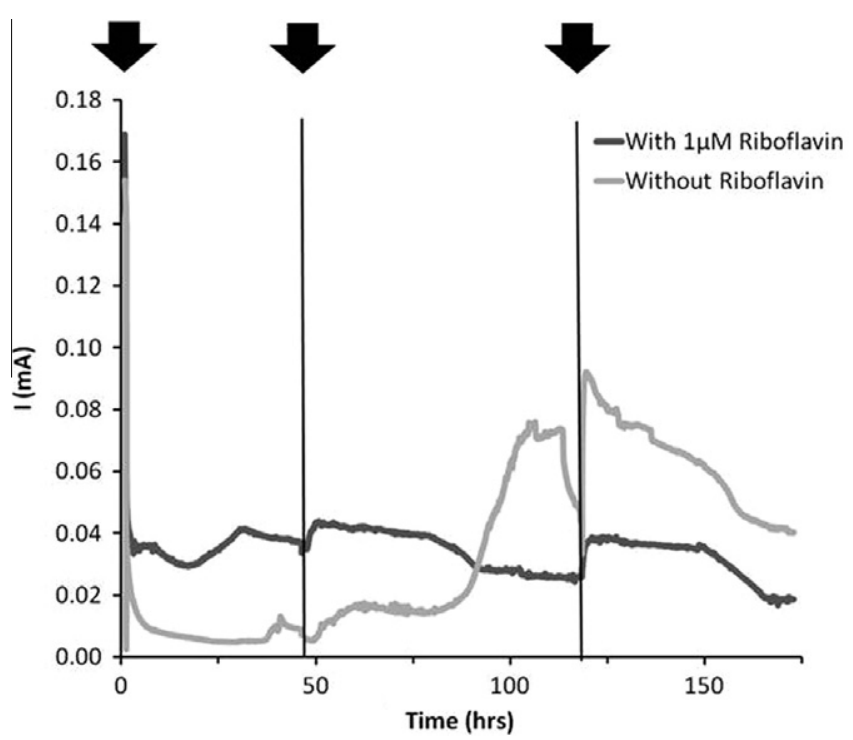

Fig. 3. Current versus time chart for $S$. japonica in the mini-MFC with and without addition of $1 \mu \mathrm{M}$ riboflavin. Footnote: Addition of $10 \mathrm{mM}$ sucrose is indicated by vertical lines.
Two very interesting phenomena were observed from the miniMFC experiments. The first was that $S$. japonica could generate twice the current (maximum current: $0.08 \mathrm{~mA}$ compared to $0.04 \mathrm{~mA}$ for riboflavin) from sucrose without addition of riboflavin after $75 \mathrm{~h}$. The second observation was that riboflavin addition could inhibit current generation even while mediating electron transfer between S. japonica and electrode. This result suggests that riboflavin at $1 \mu \mathrm{M}$ could inhibit microbial metabolism or could be a result of the microbe metabolizing riboflavin as a carbon source instead of sucrose at this concentration. However, the relationship between riboflavin concentration and bacterial metabolism should be explored further as riboflavin is being used to study fundamental mechanisms of extracellular electron transfer in cyclic voltammetric experiments.

To determine the source of the increase in current after $75 \mathrm{~h}$ in the unmediated MFC, $1 \mathrm{~mL}$ aliquots were removed from both MFCs throughout the experiment for analysis by HPLC with a refractive index detector. Fig. 4 shows data from these aliquots collected during operation of the mini-MFC (shown in Fig. 3) at 48, 51, and $110 \mathrm{~h}$ (prior to the first sucrose addition, 3 and $62 \mathrm{~h}$ after sucrose addition, respectively). The inserts in Fig. 4 are the calculated concentration of sucrose and acetate from the same mini-MFC experiment by HPLC. Substrate utilization and metabolite formation in MFC anolytes differed in response to addition of riboflavin. The mini-MFC without riboflavin consumed all sucrose by hour 110 while generating $0.25 \mathrm{mM}$ of acetate as a by-product (Fig. 4A). No other by-products were observed. These results were significantly different from those obtained from the mini-MFC containing riboflavin as acetate was not produced. The rate of sucrose metabolism was eight times faster than the MFC containing riboflavin (Fig. 4B). In addition, the differential consumption of sucrose was observed by the consistently lower current generated from the riboflavin containing mini-MFC.

Results from the qualitative analysis of the MFC anolyte suggested that, like $S$. oneidensis, S. japonica synthesizes a soluble redox mediator that could serve to facilitate extracellular electron transfer or secondary metabolite for respiration. Comparison of the culture supernatants and the MB medium revealed that riboflavin was identified in only post-culture supernatants. No evidence of a similar compound was found in extracts from the MB stock medium (data not shown). Absorbance maxima were observed at $222,268,370$ and $448 \mathrm{~nm}$ by UV-Vis spectroscopy. The compound identified in culture supernatants co-elutes with a riboflavin standard and the UV-Vis spectrum of the product and the riboflavin standard shared identical features (data not shown). However, the abnormally high current from the unmediated MFC compared to the mediated MFC suggests that riboflavin is not the only redox active molecule in the culture supernatant. Since there were sparse biofilms formed using all carbon sources from the VBSA experiment and yet large increases in current after $75 \mathrm{~h}$ in the miniMFC experiment, external mediators were the primary mechanism for electron transfer by S. japonica.

\subsection{Use of electroanalytical methods to compare mediation of oxygen reduction by $S$. japonica-exposed supernatants and by riboflavin}

Electroanalytical methods enable determination of thermodynamics and kinetics of electrochemical reactions mediated by freely diffusing redox species (Polcyn and Shain, 1966; Andrieux et al., 1980). Precise determination of rate constants for reaction between the mediator and substrate and electrochemical reduction/oxidation potentials of both the mediator species and the substrate require either large data sets which are fit to analytical expressions, or comparison of smaller data sets to digitally simulated data. Comparison of the voltammetric data generated in separate experiments will result in a qualitative comparison between 

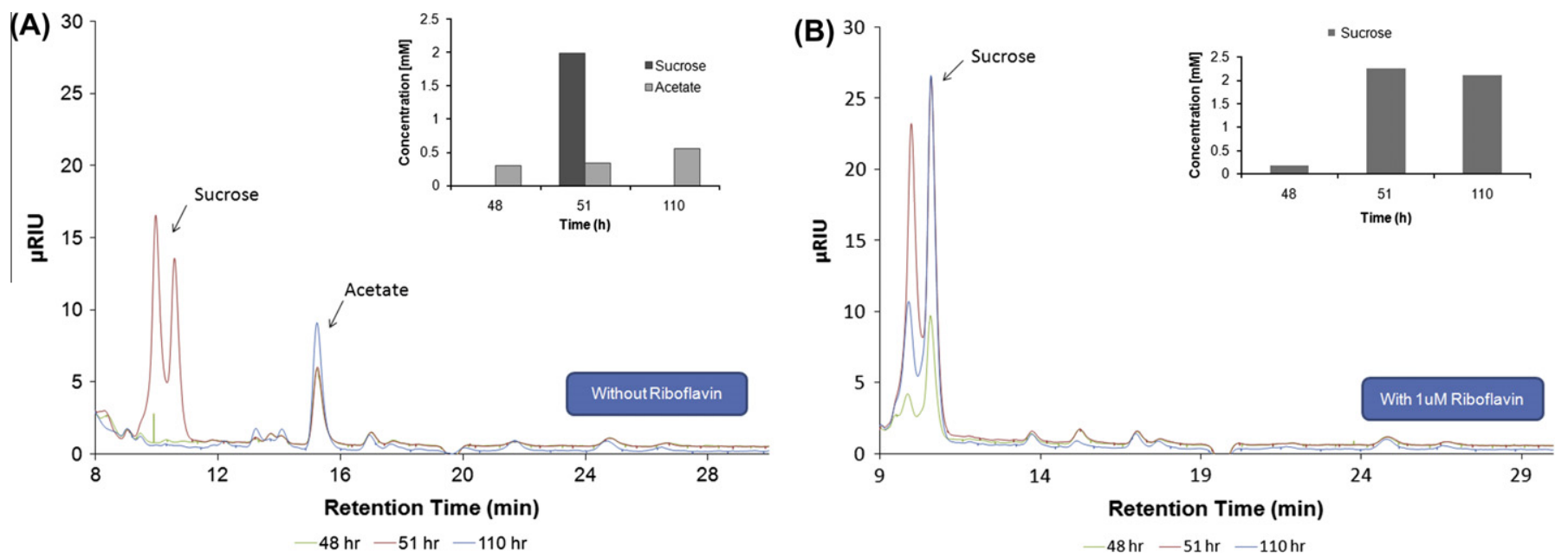

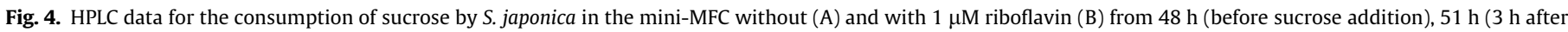

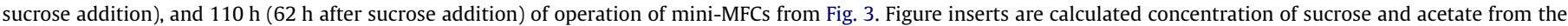
HPLC data. Footnote: Aliquot removal time from mini-MFC (Fig. 3): Green trace: 48 h; Red Trace: 51 h; Blue trace: 110 h.

two mediators which catalyze the electrochemical oxidation or reduction of the same chemical species. Using this sort of comparison, one can identify whether the two mediators are the same species or different, provided that their catalytic rates for the reaction of interest or their standard reduction potentials are sufficiently different from one another.

Cyclic voltammetry was performed separately on $S$. japonica culture supernatant, sterile MB, and MB spiked with different concentrations of riboflavin. Electrocatalytic reduction of oxygen was used as a metric for redox activity. The simplest case of mediated electrocatalysis by a freely diffusing mediator is described generally by the following three equations (Polcyn and Shain, 1966; Andrieux et al., 1980):

$A+\mathrm{ne}^{-}=B$

$P+$ ne $^{-}=Q$

$Q+A=P+B$

Eq. (1) is the direct reduction of the substrate of interest at the electrode surface. In the present experiment, $A$ represents molecular oxygen, and $B$ is the reduced form of oxygen, which will be hydrogen peroxide if $n$, the number of electrons in the reaction, is equal to two, and water if $n=4$. In Eq. (2), $P$ is the oxidized form of the electrochemical mediator and $Q$ is the reduced form of the same, and the equation represents the reduction of $P$ to $Q$ at the electrode surface. In the present experiments, $P$ represents mediators generated by $S$. japonica or an added mediator, such as riboflavin. Eq. (3) represents the electrocatalytic event, where the reduced form of the mediator reacts with the substrate to generate the reduced substrate and regenerate the oxidized mediator, represented in the present experiment by the electrocatalytic reduction of oxygen by reduced forms of $S$. japonica-derived mediators or added mediators.

Voltammograms for both the argon-saturated MB (voltammogram 1), and the argon-saturated S. japonica growth medium (voltammogram 2), featured very small cathodic peaks of $\sim 2 \mu \mathrm{A}$ at $\sim-0.47 \mathrm{~V}$ (Fig. $5 \mathrm{~A}$ ). The small peaks probably represent the reduction of trace oxygen not entirely removed from the solution. The onset of hydrogen evolution was evident around $-0.65 \mathrm{~V}$. The concentration of electrochemical mediator was below the detection limit in the CV experiment in the absence of oxygen, and the vol-
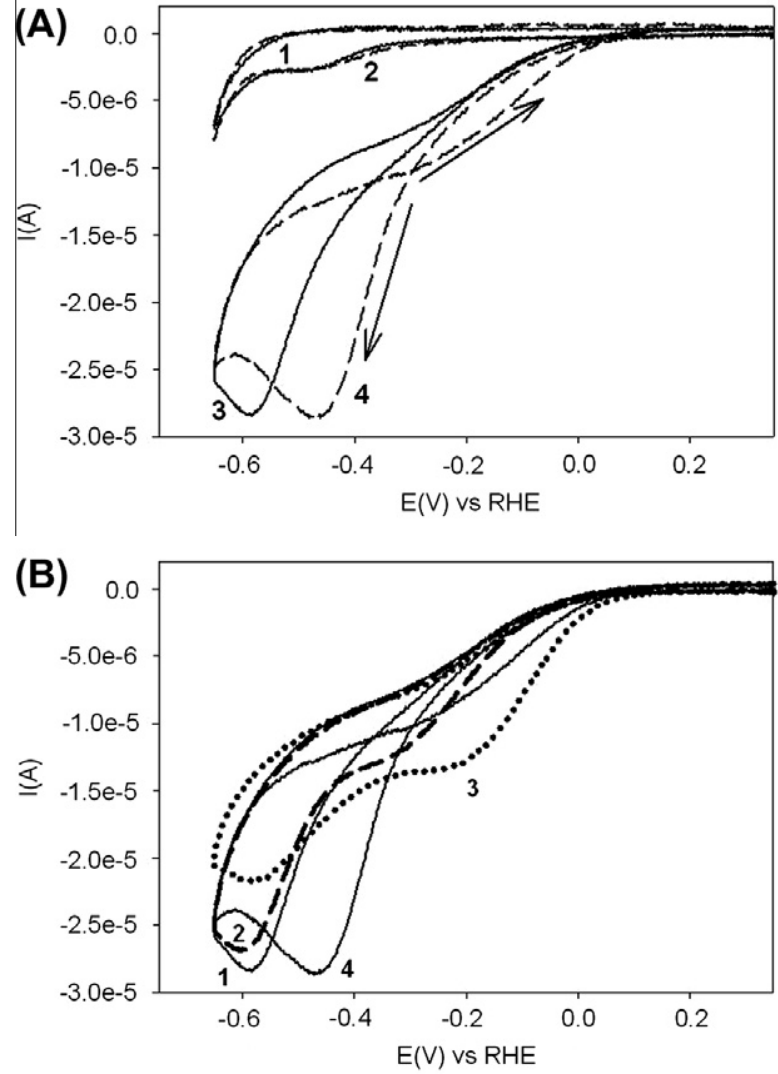

Fig. 5. (A) Cyclic voltammograms of marine broth control solution (curves 1 and 3, solid lines) and filtered S. japonica growth medium (curves 2 and 4, dashed lines) under both argon- (curves 1 and 2) and oxygen-saturated conditions (curves 3 and 4). Scan rate: $100 \mathrm{mV} / \mathrm{s}$. (B) Cyclic voltammograms of oxygen-saturated marine broth control solution (curve 1 , solid line), filtered $S$. japonica growth medium (curve 4, solid line), marine broth control solution with $1 \mu \mathrm{M}$ riboflavin (curve 2 , dashed line), and acellular marine broth control solution with $5 \mu \mathrm{M}$ riboflavin (curve 3, dotted line), Scan rate: $100 \mathrm{mV} / \mathrm{s}$.

tammograms from marine broth and culture supernatant were indistinguishable.

Under oxygen-saturated conditions, oxygen reduction was evident in both media. In MB, the oxygen reduction wave featured a cathodic peak at $\sim-0.59 \mathrm{~V}(\sim-28 \mu \mathrm{A}$ amplitude $)$, and represents 
direct reduction of oxygen at the gold electrode (voltammogram 3 ). In the $S$. japonica growth medium, the oxygen reduction wave was shifted positively by $\sim 0.13 \mathrm{~V}$, as evidenced by the $\sim-28 \mu \mathrm{A}$ cathodic peak at $\sim-0.46 \mathrm{~V}$, indicating the presence of a biogenerated redox mediator (voltammogram 4). Fig. 5B compares the mediated electrocatalysis of oxygen reduction in $S$. japonica growth medium and in MB controls spiked with riboflavin to concentrations of $0-5 \mu \mathrm{M}$. Riboflavin supplements caused diminution of the cathodic peak derived from direct oxygen reduction at the electrode (voltammograms 2 and 3 ) compared to the unmediated case (voltammogram 1) and the onset of oxygen reduction at more positive potentials. When high riboflavin concentrations $(5 \mu \mathrm{M})$ were used, the electrocatalytic wave started to take the form of a cathodic peak around $-0.2 \mathrm{~V}$ (voltammogram 3 ).

The onset potential and the general shape of the voltammograms for electrocatalysis of oxygen reduction in the riboflavinspiked controls, when compared to the voltammograms for electrocatalytic oxygen reduction in the $S$. japonica growth medium (voltammogram 4), are very different. While a detailed electroanalytical determination of the kinetic and thermodynamic parameters for the mediator present in the S. japonica growth medium is beyond the scope of the present study, the data imply that both the reduction potential for the mediator and the rate constants for the electron transfer between the mediator and oxygen are different from those for riboflavin (Andrieux et al., 1980). It is possible that some variant of riboflavin or collection of other organic redox active compounds or proteins was synthesized by $S$. japonica and served as a redox mediator in its metabolic pathway. Alternately, a different mediator altogether may be responsible for the electrocatalysis of oxygen reduction. It is clear some sort of mediator was generated by S. japonica, enabling the reduction of oxygen in the metabolic pathway of $S$. japonica and the function of $S$. japonica in the MFC.

\section{Conclusions}

The ability of S. japonica to use a diverse range of carbon sources (from monosaccharides to sucrose to agar) indicates that it may have great promise in MFC for marine environments. The reported data conclude that sucrose can be utilized for power production from $S$. japonica. Additionally, riboflavin was observed in culture supernatants and corresponded with significant increases in the current generated from a MFC but may not be the only mediator present for mediating electron transfer from S. japonica to carbon electrodes. Moreover, there was not a clear connection between biofilm formation and current output suggesting that electron transfer from the bacterium to the electrode surface was solely through mediated mechanisms not direct electrode contact.

\section{Acknowledgements}

This work was funded by the Office of Naval Research (NRL 6.2 Program Element Number 62123 N), NRL Program Element Number $61153 \mathrm{~N}$, the Air Force Office of Scientific Research (MURI program, Award No. FA9550-06-1-0292) and the AFRL research was funded by the US Air Force Research Laboratory, Materials Science Directorate (AFRL-RX).

\section{References}

Abboud, R., Popa, R., Souza-Egipsy, V., Giometti Carol, S., Tollaksen, S., Mosher Jennifer, J., Findlay Robert, H., Nealson Kenneth, H., 2005. Low-temperature growth of Shewanella oneidensis MR-1. Appl. Environ. Microbiol. 71 (2), 811816.

Andrieux, C.P., Blocman, C., Dumas-Bouchiat, J.M., M'Halla, F., Saveant, J.M., 1980. Homogeneous redox catalysis of electrochemical reactions, Part V. Cyclic voltammetry. J. Electroanal. Chem. Interfacial Electrochem. 113 (1), 19-40.
Biffinger, J., Ribbens, M., Ringeisen, B., Pietron, J., Finkel, S., Nealson, K., 2009a Characterization of electrochemically active bacteria utilizing a highthroughput voltage-based screening assay. Biotechnol. Bioeng. 102 (2), 436444.

Biffinger, J.C., Byrd, J.N., Dudley, B.L., Ringeisen, B.R., 2008a. Oxygen exposure promotes fuel diversity for Shewanella oneidensis microbial fuel cells. Biosens. Bioelectron. 23 (6), 820-826.

Biffinger, J.C., Pietron, J., Bretschger, O., Nadeau, L.J., Johnson, G.R., Williams, C.C., Nealson, K.H., Ringeisen, B.R., 2008b. The influence of acidity on microbial fuel cells containing Shewanella oneidensis. Biosens. Bioelectron. 24 (4), 900-905.

Biffinger, J.C., Pietron, J., Ray, R., Little, B., Ringeisen, B.R., 2007. A biofilm enhanced miniature microbial fuel cell using Shewanella oneidensis DSP10 and oxygen reduction cathodes. Biosens. Bioelectron. 22 (8), 1672-1679.

Biffinger, J.C., Ray, R., Little, B.J., Fitzgerald, L.A., Ribbens, M., Finkel, S.E., Ringeisen, B.R., 2009b. Simultaneous analysis of physiological and electrical output changes in an operating microbial fuel cell with Shewanella oneidensis. Biotechnol. Bioeng. 103 (3), 524-531.

Bouhenni, R.A., Vora, G.J., Biffinger, J.C., Shiodkar, S., Brockman, K., Ray, R., Wu, P.K. Johnson, B.J., Biddle, E.M., Marshall, M.J., Fitzgerald, L.A., Little, B.J., Fredrickson, J.K., Beliaev, A.S., Ringeisen, B.R., Saffarini Daad, A., 2010. The role of Shewanella oneidensis MR-1 outer membrane structures in extracellular electron transfer. Electroanalysis 22 (7-8), 856-864.

Call, D.F., Wagner, R.C., Logan, B.E., 2009. Hydrogen production by Geobacter species and a mixed consortium in a microbial electrolysis cell. Appl. Environ. Microbiol. 75 (24), 7579-7587.

Chaudhuri, S.K., Lovley, D.R., 2003. Electricity generation by direct oxidation of glucose in mediatorless microbial fuel cells. Nat. Biotechnol. 21 (10), 12291232.

Franks, A.E., Nevin, K.P., Jia, H., Izallalen, M., Woodard, T.L., Lovley, D.R., 2009. Novel strategy for three-dimensional real-time imaging of microbial fuel cell communities: monitoring the inhibitory effects of proton accumulation within the anode biofilm. Energy Environ. Sci. 2 (1), 113-119.

Fredrickson, J.K., Romine, M.F., Beliaev, A.S., Auchtung J.M., Driscoll, M.E., Gardner, T.S., Nealson, K.H., Osterman, A.L., Pinchuk, G., Reed, J.L., Rodionov, D.A Rodrigues, J.L.M., Saffarini, D.A., Serres, M.H., Spormann, A.M., Zhulin, I.B., Tiedje J.M., 2008. Towards environmental systems biology of Shewanella. Nat. Rev. Microbiol. 6 (8), 592-603.

Gorby, Y.A., Yanina, S., McLean, J.S., Rosso, K.M., Moyles, D., Dohnalkova, A., Beveridge, T.J., Chang, I.S., Kim, B.H., Kim, K.S., Culley, D.E., Reed, S.B., Romine, M.F., Saffarini, D.A., Hill, E.A., Shi, L., Elias, D.A., Kennedy, D.W., Pinchuk, G. Watanabe, K., Ishii, S.i., Logan, B., Nealson, K., Fredrickson, J.K., 2006. Electrically conductive bacterial nanowires produced by Shewanella oneidensis strain MR-1 and other microorganisms. Proc. Natl. Acad. Sci. USA 103 (30), 11358-11363.

Harnisch, F., Schroder, U., 2009. Selectivity versus mobility: separation of anode and cathode in microbial bioelectrochemical systems. Chem. Sus. Chem. 2 (10), 921-926.

Huang, J., Sun, B., Zhang, X., 2010. Electricity generation at high ionic strength in microbial fuel cell by a newly isolated Shewanella marisflavi EP1. Appl. Microbiol. Biotechnol. 85 (4), 1141-1149.

Ishii, S.i., Shimoyama, T., Hotta, Y., Watanabe, K., 2008. Characterization of a filamentous biofilm community established in a cellulose-fed microbial fuel cell. BMC Microbiol. 8 (1), 6-18.

Ivanova, E.P., Sawabe, T., Gorshkova, N.M., Svetashev, V.I., Mikhailov, V.V., Nicolau, D.V., Christen, R., 2001. Shewanella japonica sp. nov. Int. J. Syst. Evol. Microbiol. 51 (3), 1027-1033.

Jelsbak, L., Sogaard-Andersen, L., 2003. Cell behavior and cell-cell communication during fruiting body morphogenesis in Myxococcus xanthus. J. Microbiol. Methods 55 (3), 829-839.

Larminie, J., Dicks, A., 2003. Fuel Cell Systems Explained. John Wiley \& Sons Ltd. West Sussex.

Logan, B.E., Regan, J.M., 2006. Microbial fuel cells - challenges and applications. Environ. Sci. Technol. 40 (17), 5172-5180.

Lovley, D.R., 2006. Bug juice: harvesting electricity with microorganisms. Nat. Rev. Microbiol. 4 (7), 497-508.

Marsili, E., Baron, D.B., Shikhare, I.D., Coursolle, D., Gralnick, J.A., Bond, D.R., 2008 Shewanella secretes flavins that mediate extracellular electron transfer. Proc. Natl. Acad. Sci. USA 105 (10), 3968-3973.

Myers, C.R., Nealson, K.H., 1988. Bacterial manganese reduction and growth with manganese oxide as the sole electron acceptor. Science 240 (4857), 1319-1321.

Polcyn, D.S., Shain, I., 1966. Theory of stationary electrode polarography for a multistep charge transfer with catalytic (cyclic) regeneration of the reactant. Anal. Chem. 38 (3), 376-382.

Proft, T., Baker, E.N., 2009. Pili in Gram-negative and Gram-positive bacteria structure, assembly and their role in disease. Life Sci. Cell. Mol. 66 (4), 613-635.

Ramasamy, R.P., Gadhamshetty, V., Nadeau, L.J., Johnson, G.R., 2009. Impedance spectroscopy as a tool for non-intrusive detection of extracellular mediators in microbial fuel cells. Biotechnol. Bioeng. 104 (5), 882-891.

Ray, R., Little, B., Wagner, P., Hart, K., 1997. Environmental scanning electron microscopy investigations of biodeterioration. Scanning 19 (2), 98-103.

Reguera, G., Nevin, K.P., Nicoll, J.S., Covalla, S.F., Woodard, T.L., Lovley, D.R., 2006 Biofilm and nanowire production leads to increased current in Geobacter sulfurreducens fuel cells. Appl. Environ. Microbiol. 72 (11), 7345-7348.

Ren, Z., Steinberg, L.M., Regan, J.M., 2008. Electricity production and microbial biofilm characterization in cellulose-fed microbial fuel cells. Water Sci. Technol. 58 (3), 617-622. 
Rezaei, F., Xing, D., Wagner, R., Regan, J.M., Richard, T.L., Logan, B.E., 2009 Simultaneous cellulose degradation and electricity production by Enterobacter cloacae in a microbial fuel cell. Appl. Environ. Microbiol. 75 (11), 36733678.

Richter, H., Lanthier, M., Nevin, K.P., Lovley, D.R.,2007. Lack of electricity production by Pelobacter carbinolicus indicates that the capacity for Fe(III) oxide reduction does not necessarily confer electron transfer ability to fuel cell anodes. Appl. Environ. Microbiol. 73 (16), 5347-5353.

Ringeisen, B.R., Henderson, E., Wu, P.K., Pietron, J., Ray, R., Little, B., Biffinger, J.C. Jones-Meehan, J.M., 2006. High power density from a miniature microbial fuel cell using Shewanella oneidensis DSP10. Environ. Sci. Technol. 40 (8), 26292634.

Schröder, U., 2007. Anodic electron transfer mechanisms in microbial fuel cells and their energy efficiency. Phys. Chem. Chem. Phys. 9 (21), 2619-2629.
Thormann, K.M., Saville, R.M., Shukla, S., Pelletier, D.A., Spormann, A.M., 2004. Initial phases of biofilm formation in Shewanella oneidensis MR-1. J. Bacteriol. 186 (23), 8096-8104.

Von Canstein, H., Ogawa, J., Shimizu, S., Lloyd, J.R., 2008. Secretion of flavins by Shewanella species and their role in extracellular electron transfer. Appl. Environ. Microbiol. 74 (3), 615-623.

Watanabe, K., 2008. Recent developments in microbial fuel cell technologies for sustainable bioenergy. J. Biosci. Bioeng. 106 (6), 528-536.

Zhao, F., Slade, R.C.T., Varcoe, J.R., 2009. Techniques for the study and development of microbial fuel cells: an electrochemical perspective. Chem. Soc. Rev. 38 (7), 1926-1939.

Zuo, Y. Xing, D., Regan, J.M. Logan, B.E, 2008. Isolation of the exoelectrogenic bacterium Ochrobactrum anthropi YZ-1 by using a U-tube microbial fuel cell. Appl. Environ. Microbiol. 74 (10), 3130-3137. 